\title{
White spot syndrome virus envelope protein VP53A interacts with Penaeus monodon chitin-binding protein (PmCBP)
}

\author{
Li-Li Chen ${ }^{1, *}$, Li-Chen Lu ${ }^{1}$, Wan-Jung $\mathrm{Wu}^{1}{ }$, Chu-Fang $\mathrm{Lo}^{2}$, Wei-Pang Huang ${ }^{2}$ \\ ${ }^{1}$ Department of Biomedical Sciences, Chung Shan Medical University, No. 110, Sec. 1, Chien-Kuo N. Road, Taichung 402, \\ Taiwan, ROC \\ ${ }^{2}$ Institute of Zoology, National Taiwan University, No. 1, Sec. 4, Roosevelt Road, Taipei, Taiwan 10617, ROC
}

\begin{abstract}
White spot syndrome virus (WSSV) is the causative agent of a severe disease of cultivated shrimp. Using purified WSSV virions, VP53A encoded by open reading frame wssv067 was identified as a structural protein by SDS-PAGE and proteomics. Immunoelectron microscopy with a gold-labeled secondary antibody revealed that VP53A was distributed on the viral envelope. In order to further explore the link between WSSV067 and host proteins, we performed a yeast 2-hybrid screening of a Penaeus monodon cDNA library, using WSSV067C as bait. One of the molecules that specifically interacted with WSSV067C was the $P$. monodon chitin-binding protein (PmCBP). An in vitro binding assay showed that c-myc-WSSV067C was capable of co-precipitating HA-PmCBP-C. Furthermore, PmCBP was expressed in almost all organs but appeared to be up-regulated at the late stage of WSSV infection.
\end{abstract}

KEY WORDS: Penaeus monodon - White spot syndrome virus · VP53A · Envelope protein · Chitin-binding protein

Resale or republication not permitted without written consent of the publisher

\section{INTRODUCTION}

White spot syndrome (WSS) has now become the most serious disease affecting the global shrimp aquaculture industry. The causative agent, white spot syndrome virus (WSSV), is an enveloped, ellipsoid, large, and double-stranded DNA virus (Wang et al. 1995, Wongteerasupaya et al. 1995, Lo et al. 1996a) that has a wide host range among crustaceans (Lo et al. 1996b, Flegel 1997, Lo \& Kou 1998). The size of the WSSV genome has been reported to differ among isolates, and varies from 305107 bp (GenBank Accession No. AF332093) to 292967 bp (GenBank Accession No. AF369029) and 307287 bp (GenBank Accession No. AF440570) for viruses isolated from China, Thailand and Taiwan, respectively. Recent research on WSSV structure using proteomic methods has revealed that its structural proteins have increased in number to 39 (Tsai et al. 2004). Now, research activities have begun to focus on the protein-protein interactions between the shrimp and virus, between shrimp proteins, and between virus proteins (Lu \& Kwang 2004, Tonganunt et al. 2005, Wang et al. 2005, Xie \& Yang 2005). According to previous studies by Tsai et al. (2004, 2006), VP53A encoded by WSSV gene wsSV067 is an envelope protein. Proteomic data indicates that VP53A (molecular weight $53 \mathrm{kDa}$ ) comprises the $\mathrm{C}$ terminus of WSSV067 that codes for a deduced protein of $150 \mathrm{kDa}$. We selected WSSV067C as the bait to perform a yeast 2-hybrid screen of a Penaeus monodon cDNA library. A positive clone containing a conserved chitin-binding Type 2 domain was obtained. Chitin-binding proteins (CBPs) such as chitinase and lectin that contain a chitin-binding Type 2 domain are known to participate in immune responses (Tjoelker et al. 2000, Gaines et al. 2003).

\section{MATERIALS AND METHODS}

Virus and genomic plasmid libraries. WSSV collected from infected Penaeus monodon (Wang et al. 1995) from Taiwan in 1994 was used to construct WSSV genomic libraries (Lo et al. 1996a, Tsai et al. 
2000, Liu et al. 2001). This virus source has been maintained in our laboratory since 1994 (GenBank Accession No. AF440570). It was previously known simply as the WSSV Taiwan isolate (Lo et al. 1999), but to distinguish it from other WSSV Taiwan isolates, it will henceforth be referred to as the WSSV Taiwan-1 strain (WSSV T-1 strain). WSSV T-1 strain was used as the basis for all of the WSSV genome sequence research conducted in the present study.

Antibody preparation. The DNA sequence encoding 200 deduced amino acids from the WSSV067 C-terminus was amplified from WSSV-infected shrimp by PCR with the 067CFBamHI/067CRSall primer set (5'GGGGATCCGATAACGGTTGAAGGAGTC-3'/5'-GG AAGCTTTTACATCAACACTGTAACTGC-3'; the underlined bases indicate respectively the BamHI and HindIII restriction sites that were used for subsequent cloning) and ligated to pGEM-T Easy (Promega). After confirming the sequence, the resulting plasmid pGEM-T-VP53AC was cleaved with BamH1 and Sal1, and the amplified fragment was then cloned to pET28b(+) (Novagen) at BamHI and HindIII sites. The resulting $\mathrm{pET}$-VP53AC clone was transformed into BL21 Codon Plus Escherichia coli cells (Stratagene). For protein expression and purification, cells were grown overnight at $37^{\circ} \mathrm{C}$ in Luria-Bertani (LB) media supplemented with $50 \mu \mathrm{g} \mathrm{ml}^{-1}$ kanamycin and $34 \mathrm{\mu g}$ $\mathrm{ml}^{-1}$ chloramphenicol. The cells were inoculated into new media at a ratio of $1: 300$, and grown at $37^{\circ} \mathrm{C}$ for 1.5 to $2 \mathrm{~h}$. Expression was induced by addition of $1 \mathrm{mM}$ isopropyl $\beta$-D-1-thiogalactopyranoside (IPTG) and incubation was continued for another 1.5 to $3 \mathrm{~h}$. The induced bacteria were spun down at $4{ }^{\circ} \mathrm{C}$, suspended in ice-cold phosphate-buffered saline (PBS) containing $10 \%$ glycerol and a Protease Inhibitor Cocktail tablet (Roche Molecular BioChemicals), and sonicated for $30 \mathrm{~s}$ on ice. The insoluble debris was collected by centrifugation, suspended with PBS containing 1.5\% sodium lauryl sarcosine, and solubilized by shaking at $4^{\circ} \mathrm{C}$ for $2 \mathrm{~h}$. The supernatant was clarified by centrifugation and mixed with Ni-NTA agarose beads (Quiagen) on a rotary wheel at $4^{\circ} \mathrm{C}$ for $16 \mathrm{~h}$ or overnight. The beads were then washed several times with ice-cold wash buffer (1M NaCl, $10 \mathrm{mM}$ Tris- $\mathrm{HCl}, \mathrm{pH} 7.5)$ to remove unbound material. The fusion proteins were directly eluted from the beads with SDS sample buffer and subjected to SDS-PAGE analysis. The protein bands containing the fusion proteins were sliced from the gel, minced, mixed with Freund's adjuvant and used for antibody production.

Localization of VP53A by immunoelectron microscopy (IEM). A purified WSSV virion suspension was adsorbed to Formvar-supported and carbon-coated nickel grids (150 mesh) and incubated for $5 \mathrm{~min}$ at room temperature. The primary antibody and pre- immune rabbit serum were diluted to a 1:50 ratio in incubation buffer $(0.1 \%$ AURION BASIC-c, $15 \mathrm{mM}$ $\mathrm{NaN}_{3}, 10 \mathrm{mM}$ phosphate buffer, $150 \mathrm{mM} \mathrm{NaCl}$, $\mathrm{pH}$ 7.4). The grids were blocked with blocking buffer (5\% BSA, 5\% normal serum, $0.1 \%$ cold water skin gelatin, $10 \mathrm{mM}$ phosphate buffer, $150 \mathrm{mM} \mathrm{NaCl}$, $\mathrm{pH}$ 7.4) for $15 \mathrm{~min}$ and then incubated with the diluted primary antibody or pre-immune rabbit serum for $1 \mathrm{~h}$ at room temperature. After several washes with incubation buffer, the grids were incubated with goat antirabbit secondary antibody conjugated with $6 \mathrm{~nm}$ or $15 \mathrm{~nm}$ diameter gold particles (1:40 dilution ratio in incubation buffer) for $1 \mathrm{~h}$ at room temperature. The grids were then washed extensively with incubation buffer, washed twice more with distilled water to remove excess salt and stained with $2 \%$ phosphotungstic acid (PTA, pH 7.2) for $30 \mathrm{~s}$. Specimens were examined by transmission electron microscopy (TEM).

Tissue tropism analysis of PmCBP, temporal analysis of WSSV067 and PmCBP transcription by RT-PCR. The stomach, gills, midgut, haemolymph, lymphoid organ, hepatopancreas, haematopoietic tissue, pleopods, nervous tissue and heart were collected from Penaeus monodon without artificial WSSV infection. To date, no WSSV-susceptible shrimp cell lines have become available; therefore, all RNA for the transcriptional analysis was taken from different tissues of WSSV-infected shrimp at various times after infection, using procedures described by Chen et al. (2002a). Total RNA was isolated as described previously (Tsai et al. 2000, Liu et al. 2001). The procedure for cDNA synthesis and primer sets for $v p 26, v p 28$ and actin were all as previously described by Chen et al. (2002a). A WSSV genomic DNA-specific primer set IC-F2/IC-R3 (5'-CAGACTATTAATGTACAAGTGCG-3'/5' -GAATGATTGTTGCTGGTTAGAACC-3'), derived from an inter-genic region of the WSSV genome, was used to confirm that the RNA was not contaminated by any viral DNA. The cDNA reaction products were subjected to PCR with the primer sets 067-RTF2/067-RTR8 (GATCCACATTCTCCTTGAGC/CGTCCAAGTTAGT GCCGATT) for WSSV067 and PmCBP-RT-F1/PmCBPRT-R1 (5'-GGCAGTGGATTCACTGGATC-3'/5'-TGT TCGCATGAGTTGTTCATTG-3') for PmCBP.

Yeast 2-hybrid assay. The plasmids, yeast strains and library construction kits used in this experiment were all adopted from BD Matchmaker library construction and screening kits (BD Biosciences Clontech).

Plasmid construction: The DNA sequence encoding the 577 deduced amino acids from the WSSV067 C-terminus was amplified by PCR with the Y2H-WSSV067C F/R primer set (5'-ATTGAGCGCCCCGGGGACGA3'/5'-ATGTGGATCCTTACCTATCCATTTTTATGA-3'; the underlined bases indicate respectively the SmaI 
and BamHI restriction sites that were used for subsequent cloning) from WSSV-infected shrimp, and ligated to pGEM-T Easy (Promega). After confirming the sequence, the resultant plasmid pGEM-T-WSSV067C was cleaved with SmaI and BamHI, and the amplified fragment was then subcloned in frame into the bait vector pGBKT7 that encodes a GAL4 DNA-binding domain. The plasmid was named BD-WSSV067C.

Library construction: Total RNA was isolated from Penaeus monodon postlarvae 15 to 20 using Trizol reagent (Invitrogen). About $5 \mu \mathrm{g}$ of total RNA was used to generate cDNA that was ligated into the pGADT7Rec prey vector and then transformed into Saccharomyces cerevisiae strain AH109, according to the instructions provided by the manufacturer.

Screening: The bait vector BD-WSSV067C was used to screen independent recombinant clones of the cDNA library in Saccaromyces cerevisiae strain Y187. After mating the library host strain with the bait strain, positive clones were selected for growth on a synthetic dropout (SD) plate lacking adenine, histidine, leucine and tryptophan (SD/-ade/-his/-leu/-trp) and containing 5-bromo-4-chloro-3-indolyl- $\alpha$-D-galactopyranoside $(\mathrm{X}-\alpha-\mathrm{Gal})$. Plasmid DNA was isolated from those clones that activated all 4 yeast reporter genes $(A D E 2$; $H I S 3$; MEL1, encoding $\alpha$-galactosidase; and lacZ, encoding $\beta$-galactosidase) and transformed into E. coli strain JM109 to recover the plasmid for sequencing. Gene database searches were performed through the National Center for Biotechnology Information (NCBI) using the basic local alignment search tool (BLAST). The longest cDNA clone encoding the Penaeus monodon chitin-binding protein (PmCBP) was designated AD-PmCBP-C (see Fig. 4 for sequence). To confirm the screening result, recovered plasmids (containing both BD-WSSV067C and AD-PmCBP-C) were re-transformed back into a host strain and plated on SD/-ade/his/-leu/-trp. Positive interactions were re-tested by cotransforming bait and prey plasmids into Saccaromyces cerevisiae strain AH109 according to the manufacturer's instructions. Murine p53 (BD-p53) and SV40 large T-antigen (AD-T) that were supplied with the BD Matchmaker library construction and screening kits were used as positive controls. Negative controls employed pGBKT7 (BD only) and pGADT7-Rec (AD only).

In vitro transcription and translation. In vitro transcription and translation were performed under RNase-free conditions. BD-WSSV067C and ADPmCBP-C DNA $(1 \mu \mathrm{g})$ were respectively added to TNT Quick Master Mix (Promega) containing ${ }^{35} \mathrm{~S}$-methionine to yield c-myc-WSSV067C and HA-PmCBP-C fusion proteins, and the mixture was incubated at $30^{\circ}$ for 60 to $90 \mathrm{~min}$ according to the manufacturer's instructions.
Co-immunoprecipitation and SDS-PAGE analysis. In vitro-translated c-myc-WSSV067C and in vitrotranslated HA-PmCBP-C were combined in a $1.5 \mathrm{ml} \mathrm{mi-}$ crocentrifuge tube and incubated at room temperature for $1 \mathrm{~h}$. For the co-immunoprecipitation assay, protein A agarose (Amersham Pharmacia) was washed twice with PBS and restored to a $50 \%$ slurry with PBS. The optimal amount of c-myc monoclonal antibody or HATag polyclonal antibody was added to the TNT reactants, followed by incubation at room temperature for $1 \mathrm{~h}$. In order to capture the immunocomplex, an optimal amount of protein A agarose bead slurry was added to the TNT reactant/antibody mixture and gently rocked for at least $1 \mathrm{~h}$. The agarose beads were collected by centrifugation at $13000 \times g$ at $4^{\circ} \mathrm{C}$ for $5 \mathrm{~min}$ and then washed 3 times with modified RIPA buffer $(50 \mathrm{mM}$ Tris$\mathrm{HCl}, \mathrm{pH} 7.4,1 \%$ nonylphenyl-polyethylthylene 40 (NP40), $0.25 \%$ Na-deoxycholate, $150 \mathrm{mM} \mathrm{NaCl}, 1 \mathrm{mM}$ EDTA, $1 \mathrm{mM}$ phenylmethylsulfonyl fluoride (PMSF), $1 \mu \mathrm{g} \mathrm{ml}^{-1}$ aprotinin, $1 \mu \mathrm{g} \mathrm{ml}^{-1}$ leupeptin, $1 \mu \mathrm{g} \mathrm{ml}^{-1}$ pepstatin, $1 \mathrm{mM} \mathrm{Na}_{3} \mathrm{VO}_{4}, 1 \mathrm{mM} \mathrm{NaF}$ ). The beads were resuspended with PBS and then subjected to SDS-PAGE analysis to check the radiography.

Chitin-binding assay. Commercially available chitin beads (New England BioLabs, catalogue no. 6651S; prepared from shrimp Pandulus borealis chitin) were used to test binding. One volume of chitin beads was washed 3 times with 10 volumes of binding buffer $(0.5 \mathrm{M} \mathrm{NaCl}$, $10 \mathrm{mM}$ Tris, $\mathrm{pH} 7.0,0.05 \%$ Triton-X-100) before assay. After in vitro transcription and translation as described above, a $10 \mu \mathrm{l}$ aliquot was removed (labeled as unbound protein) and the reactants were mixed with pre-washed chitin beads by gently shaking for $4 \mathrm{~h}$ at room temperature. The supernatant was removed and kept after centrifugation. The pellet was washed twice with $\mathrm{NaCl}$-Tris buffer ( $5 \mathrm{mM} \mathrm{NaCl}, 5 \mathrm{mM}$ Tris-Cl, $\mathrm{pH}$ 7.0). The beads were resuspended with PBS and then subjected to SDSPAGE analysis. In this experiment, murine p53 (described above) was used as the control.

\section{RESULTS}

\section{Identification of WSSV structural protein VP53A}

RT-PCR analysis was used to detect VP53A-specific transcripts in DNase-treated total RNA from shrimp specimens before injection $(0 \mathrm{~h})$ and at $2,4,6,8,12,18$, 24,36 and $60 \mathrm{~h}$ after intramuscular injection of WSSV. After 30 cycles of amplification, the transcripts were detected at low levels by 4 to $8 \mathrm{~h}$ post-injection (p.i.), increased at $12 \mathrm{~h}$ p.i. and remained fairly constant thereafter (Fig. 1). The overall transcriptional pattern of $w s s v 067 C$ was similar to those of $v p 26$ and $v p 28$ (which are known as late genes encoding WSSV struc- 

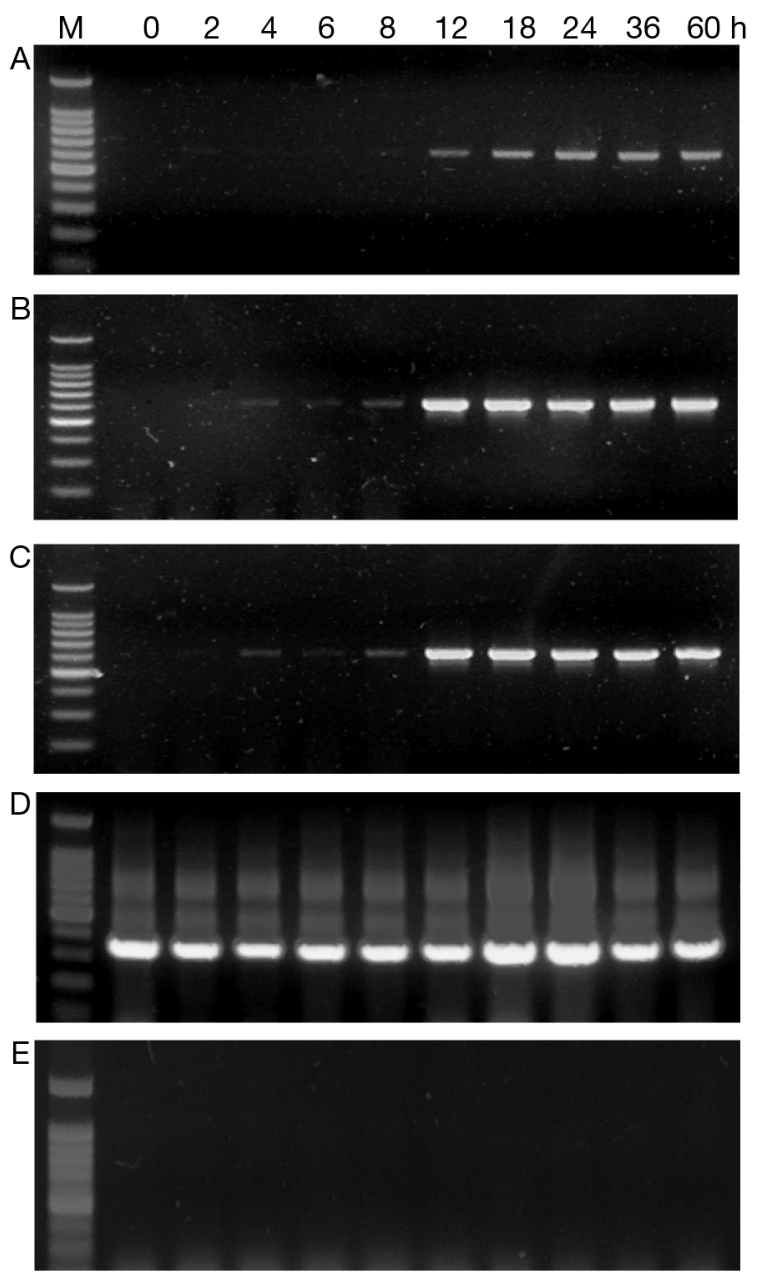

Fig. 1. Temporal transcription analysis of WSSV (A) wsSv067, (B) $v p 26$ and (C) vp28 genes by RT-PCR. Internal controls: total RNA treated with DNase and amplified with (D) actinspecific primers and (E) intergenic primers. Products were resolved in $1 \%$ agarose gel containing $0.5 \mathrm{\mu g} \mathrm{ml}^{-1}$ ethidium bromide. Lane M is a 100 bp DNA ladder (Promega); other lane headings show time (h) post-injection

tural proteins) and unlike the WSSV early genes dnapol, rr1 and rr2 (Chen et al. 2002b).

Immunoelectron microscopy confirmed that VP53A was localized in the envelope of the intact virus (Fig. 2A-D) and was not found when the envelope was removed (Fig. 2G). A similar result showed that an antibody against VP28 - one of the WSSV envelope proteins - also binds to the viral envelope (Fig. 2E,F).

\section{Identification of PmCBP}

To identify the shrimp proteins that bound WSSV067, we performed a yeast 2-hybrid screen with a 577 amino acid fragment of WSSV067 that con-
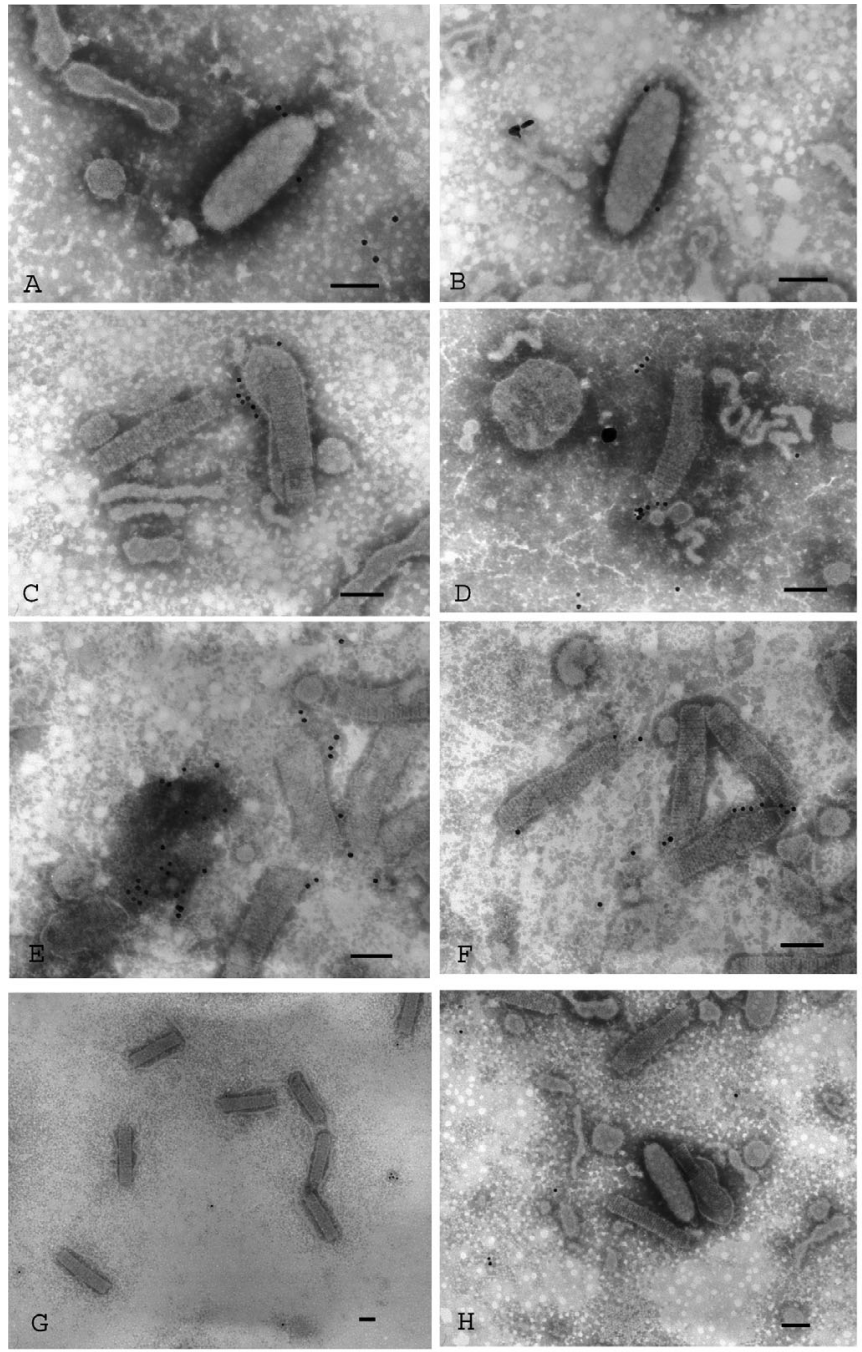

Fig. 2. Immunoelectron microscopy analysis of purified virions probed with VP53A antibody. (A), (B), (C) and (D) show that the antibody specifically binds to the viral envelope, not the nucleocapsid; (E) and (F) show that the antibody against VP28 also binds to the viral envelope; $(G)$ shows that the antibody does not bind to the purified nucleocapsid; $(\mathrm{H})$ shows that pre-immune rabbit antibody does not bind to the virions. Scale bar $=100 \mathrm{~nm}$

tained the C-terminal transmembrane domain (TMD) (WSSV067C, including the full length of VP53A) as bait. The screening of the cDNA library led to the isolation of 15 independent clones that were further sequenced and aligned with the NCBI or expression sequence tag (EST) database (unpubl. data) (Fig. 3). Among the clones, 9 consisted of the same incomplete cDNA that contained a conserved chitin-binding Type 2 domain, which is characterized by having a 6-cysteine motif and several aromatic residues (Fig. 4). We named this protein Penaeus monodon chitin-binding protein (PmCBP).

The positive clone, PmCBP C terminus (PmCBP-C), was retransformed into the yeast strain $\mathrm{AH} 109$ to retest 


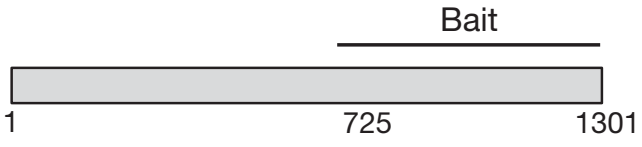

\begin{tabular}{|l|c|}
\hline \multicolumn{1}{|c|}{ Clone } & Positive no. \\
\hline Actin & 1 \\
\hline Myosin & 1 \\
\hline EST clone & 4 \\
\hline $\begin{array}{l}\text { P. monodon chitin-binding } \\
\text { protein (PmCBP) }\end{array}$ & 9 \\
\hline
\end{tabular}

Fig. 3. Schematic indicating the localization of bait (BD-WSSV 067C) and the positive clones obtained using the yeast 2-hybrid screen

its putative interaction with WSSV067C. Murine p53 (BD-p53) and SV40 large T-antigen (AD-T) were used as positive controls. Negative controls employed pGBKT7 (BD only) and pGADT7-Rec (AD only). Yeast expressing BD-WSSV067C and AD-PmCBP-C formed

GGCAGTGGATTCACTGGATCCCAGTCTGGTTCATCAGGTGCCACTGGCTTCCAATCTGGA 60 $\begin{array}{lllllllllllllllllllll}G & S & G & F & T & G & S & Q & S & G & S & S & G & A & T & G & F & \varrho & S & G & 20\end{array}$ TCTGGCAGTGGATTCGGTCTTTCATCAGGATTTGGCGGATTCCTGTCTGGTTCAAGTGGT 120 $\begin{array}{lllllllllllllllllllll}S & G & S & G & F & G & L & S & S & G & F & G & G & F & L & S & G & S & S & G & 40\end{array}$ GCTGGATTTGGGGCAGCAGGTGGCAGTGGACTTCAGTTTGGTTCAGAATCAGATGATGTA 180 $\begin{array}{lllllllllllllllllllll}A & G & F & G & A & A & G & G & S & G & L & Q & F & G & S & E & S & D & D & V & 60\end{array}$ TTTGGTATCTTTGAGCCTCTGAATCTTCCTGCAGAAGCCACTCGCTTGCTTGGAAAAATC 240 $\begin{array}{lllllllllllllllllllll}F & G & I & F & E & P & L & N & L & P & A & E & A & T & R & L & L & G & K & I & 80\end{array}$ TCAACATCATTTGCCTGCCTTGATCGGCCTTATGGATATTATGCTGATGAAGAAAACTCC 300 $\begin{array}{lllllllllllllllllllll}S & T & S & F & A & C & L & D & R & P & \underline{Y} & G & \underline{Y} & \underline{Y} & \text { A } & \text { D } & \text { E } & \text { E } & \text { N } & \text { S } & 100\end{array}$ TGTCACATCTTCCACATCTGTTACCCTGCTCTCTTTGCTAATGGTGTTATCGAGACCTCC 360 $\begin{array}{lllllllllllllllllllll}\text { C } & \text { H } & \text { I } & \underline{F} & \text { H } & \text { I } & \text { C } & \underline{Y} & \text { P } & \text { A } & \text { L } & \text { F } & \text { A } & \text { N } & \text { G } & \text { V } & \text { I } & \text { E } & \text { T } & \text { S } & 120\end{array}$ CAGTACAGCTTCCTGTGTGGTGAGGGTTCTCGATTCGACCAAAAGGAGCTTACTTGCGTG 420 $\begin{array}{lllllllllllllllllllll}\ell & \underline{Y} & S & \underline{F} & L & C & G & E & G & S & R & \underline{F} & D & Q & K & E & \text { L } & \text { T } & C & V & 140\end{array}$ GCAGAATCAGAAGCAATTCCTTGCCAGGAATCTTCCAACTTCTTTTTCAAGAACGAACAG 480 $\begin{array}{lllllllllllllllllllll}\text { A } & \text { E } & \text { S } & \text { E } & \text { A } & \text { I } & \text { P } & \text { C } & \text { Q } & \text { E } & \text { S } & \text { S } & \text { N } & \text { F } & \text { F } & \text { F } & \text { K } & \text { N } & \text { E } & \text { Q } & 160\end{array}$ TTTGGTCTTCCAAAGAAAAGATTTAAGCCATTTCAGCCCACTTTGAGGACTTGATGTAT 540 $\begin{array}{llllllllllll}F & G & L & P & K & E & K & I & * & 168\end{array}$

CGCCCAATGAACAACTCATGCGAACATTTTGGATAAATAAAATGG

Fig. 4. Primary structure of the longest cDNA clone, designated AD-PmCBP-C, encoding the Penaeus monodon chitin-binding protein (PmCBP). Chitin-binding Type 2 domain is in bold. In this domain, cysteine residues (shaded) and aromatic residues (underlined) are indicated
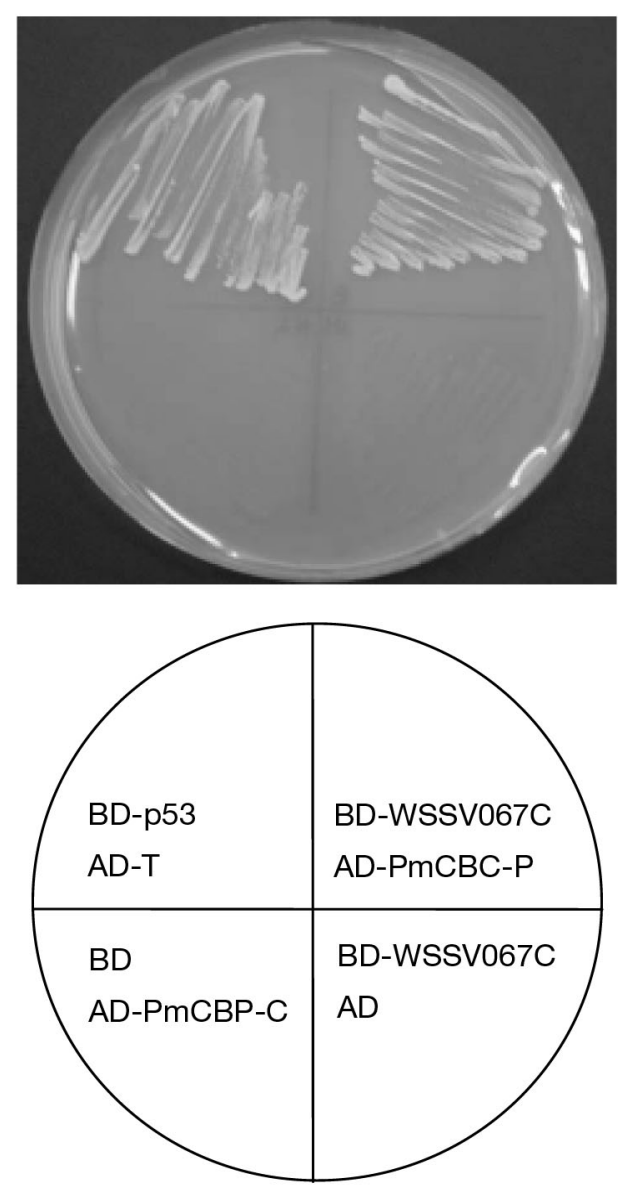

Fig. 5. Yeast 2-hybrid screen. Transformed cells were selected on synthetic dropout (SD/-ade/-his/-leu/-trp) medium.

Plasmids used are described in 'Materials and methods'

colonies on SD medium lacking adenine, histidine, leucine and tryptophan (Fig. 5). The results suggested strongly that, in yeast, WSSV067C (VP53A) and PmCBP-C interact, and that examination of this interaction under different conditions was warranted.

\section{In vitro binding assay}

To confirm the interaction between WSSV067C (VP53A) and PmCBP-C, we carried out an in vitro coimmunoprecipitation. C-myc-WSSV067C, the myc tag-containing fusion protein expressed by BDWSSV067C, and HA-PmCBP-C, the HA tag-containing fusion protein expressed by AD-PmCBP-C, were expressed by in vitro transcription and translation described in 'Materials and methods'. The C-myc monoclonal antibody and HA-tag polyclonal antibody coupled with protein A agarose were used to purify the specific proteins. As shown in Fig. 6, protein A agarose conjugated with c-myc antibody could capture c-myc- 


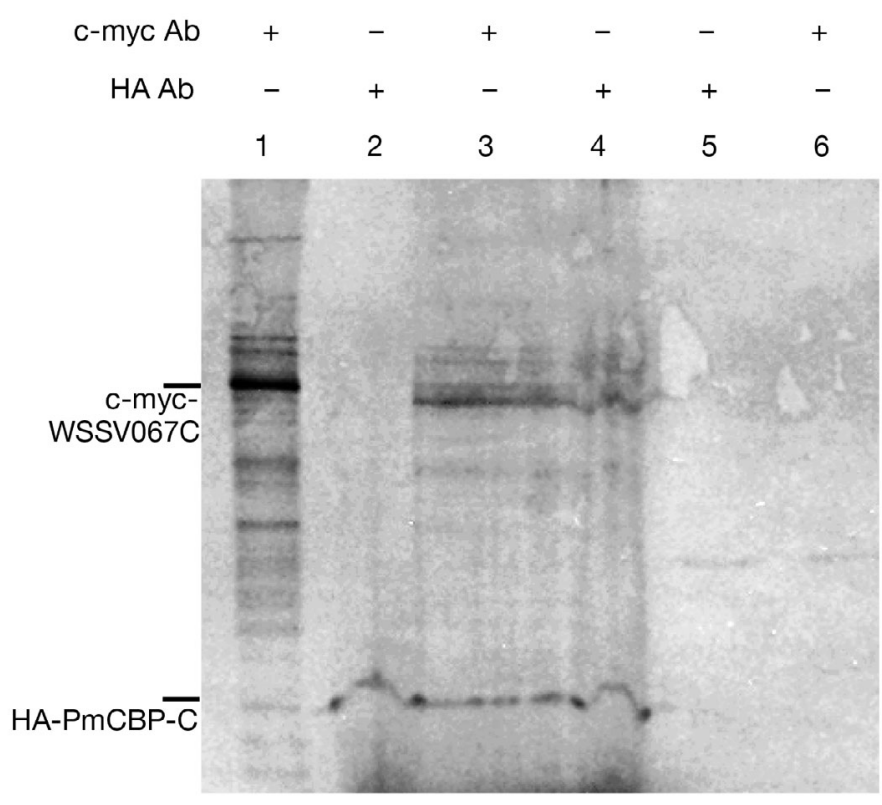

Fig. 6. SDS-PAGE analysis of WSSV067C co-immunoprecipitation with PmCBP-C. ${ }^{35}$ S-methionine was included in the translation mixture to generate radioactively labeled products c-myc-WSSV067C and HA-PmCBP-C. Lane 1: c-mycWSSV067C + c-myc antibody (c-myc Ab, ø); Lane 2: HA-PmCBP-C + HA antibody (HA Ab, ø); Lane 3: c-myc-WSSV067C + HA-PmCBP-C + c-myc antibody; Lane 4: c-myc-WSSV067C + HA-PmCBP-C + HA antibody; Lane 5: c-myc-WSSV067C + HA antibody; Lane 6: HA-PmCBP-C + C-myc antibody

WSSV067C (Lane 1) but not HA-PmCBP-C (Lane 6), and protein A agarose conjugated with HA antibody could capture HA-PmCBP-C (Lane 2) but not c-mycWSSV067C (Lane 5). After incubating c-mycWSSV067C together with HA-PmCBP-C, protein A agarose conjugated with $\mathrm{C}-\mathrm{myc}$ antibody could capture both c-myc-WSSV067C and HA-PmCBP-C (Lane 3), and protein A agarose conjugated with HA antibody could also capture both c-myc-WSSV067C and HAPmCBP-C (Lane 4).

\section{Chitin-binding assay}

A chitin-binding assay was performed to determine whether PmCBP was capable of binding to chitin in the form of commercially available chitin beads prepared from shrimp Pandulus borealis chitin. HA-PmCBP-C, expressed by the in vitro transcription and translation system, bound to the chitin beads (Fig. 7) when compared with the control group p53 (Fig. 7B, Lane 5). PmCBP-C containing the conserved chitin-binding Type 2 domain was capable of binding to chitin (Fig. 7A, Lane 5). This indicates that the PmCBP is a chitin-binding protein.

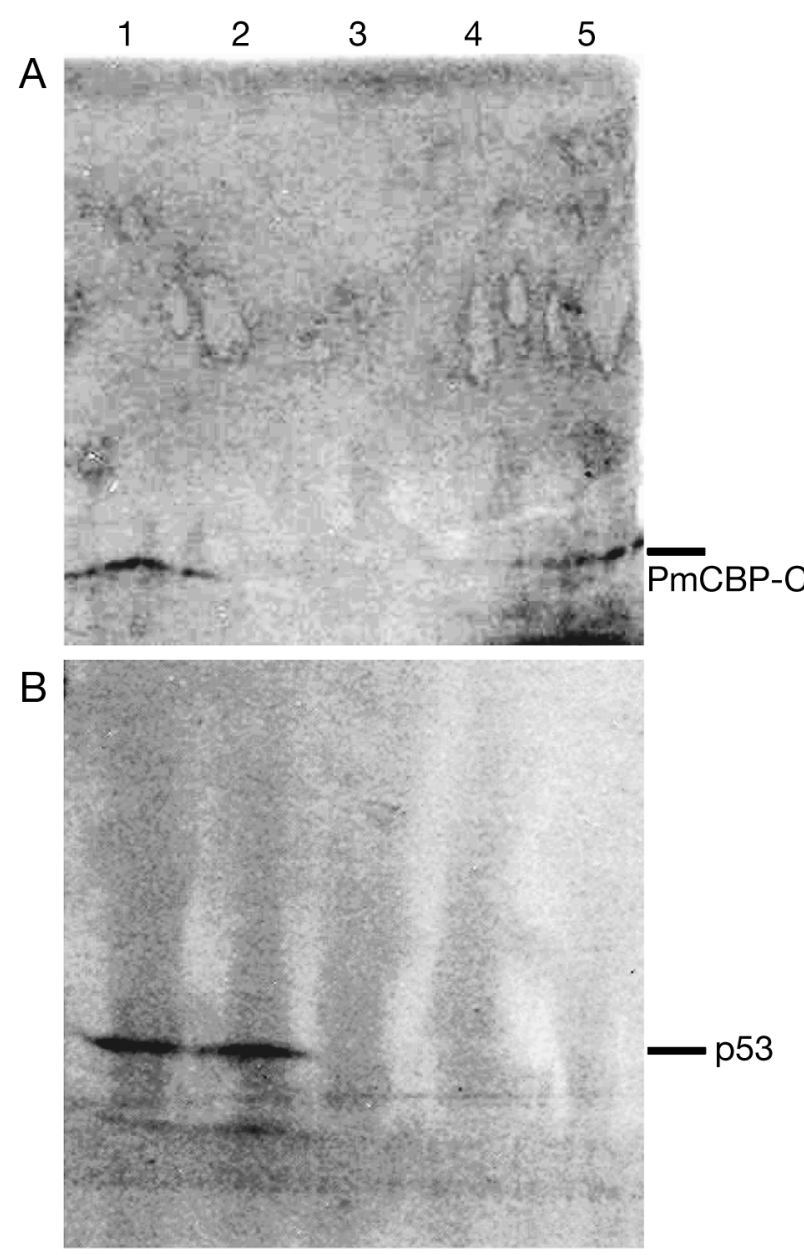

Fig. 7. SDS-PAGE analysis showing PmCBP-C binding with chitin beads. ${ }^{35} \mathrm{~S}$-methionine was included in the translation mixture to generate radioactively labeled products (A) PmCBP-C and (B) murine p53. Lane 1: unbound proteins; Lane 2: supernatants after centrifuging; Lanes 3 and 4: NaCl-Tris wash aliquots; Lane 5: chitin beads

\section{Tissue tropism and expression pattern of PmCBP}

RT-PCR was used to reveal the tissue tropism of PmCBP. PmCBP was expressed in almost all organs including the stomach, gills, midgut, haemolymph, lymphoid organ, hepatopancreas, haematopoietic tissue, pleopods, nervous tissue and heart (Fig. 8A). Time-course RT-PCR analysis of total RNA samples from WSSV-infected shrimps revealed no significant changes in PmCBP during infection (Fig. 8C). This indicated that PmCBP was constitutively expressed.

\section{DISCUSSION}

As shown in Fig. 3, the screening of the cDNA library led to the isolation of 2 kinds of cytoskeletal 

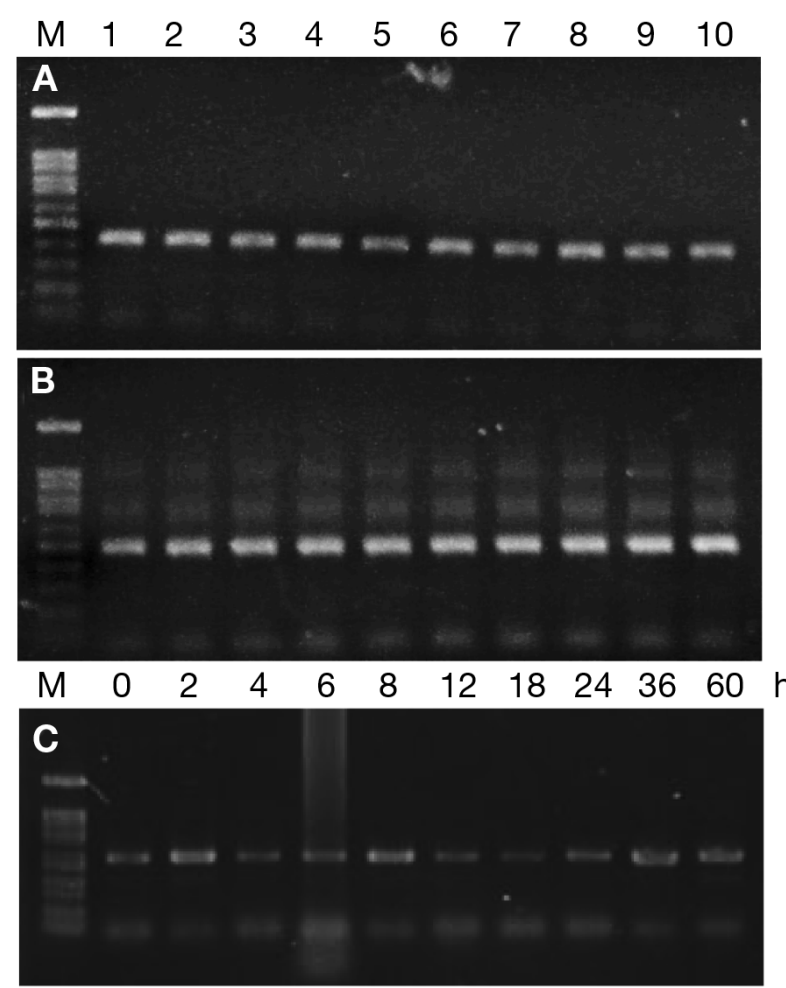

Fig. 8. Tissue tropism and temporal transcription analysis of CBP. RNA samples were extracted from organs of Peneaus monodon that were not infected with WSSV and amplified with (A) PmCBP-specific primer sets PmCBP-RT-F1/PmCBPRT-R1 or (B) actin-specific primers. (C) Time-course transcription analysis after WSSV injection using the same tested samples as in Fig. 1. Products were resolved in $1 \%$ agarose gel containing $0.5 \mu \mathrm{g} \mathrm{ml}^{-1}$ ethidium bromide. Lane $\mathrm{M}$ is a $100 \mathrm{bp}$ DNA ladder (Promega). Other lane headings show $(\mathrm{A}, \mathrm{B})$ Lane 1: stomach; Lane 2: gills; Lane 3: midgut; Lane 4: haemolymph; Lane 5: lymphoid organ; Lane 6: hepatopancreas; Lane 7: haematopoietic tissue; Lane 8: pleopods; Lane 9: nervous tissue; Lane 10: heart; (C) time (h) post-injection

proteins: myosin and actin. Similar results were revealed by Xie \& Yang (2005) who used VP26 as bait. Some viruses, such as polyomavirus simian virus 40 , vaccinia virus, herpesvirus, adenovirus etc. have been reported to exploit the host cytoskeleton in often very fascinating ways in order to facilitate important aspects of their life cycle such as entry, egress and intercellular spread (Sasaki et al. 1995, Favoreel et al. 2005, Gouin et al. 2005, Lehmann et al. 2005). Much of the proteinprotein interaction with the host cytoskeleton occurs via virus structural proteins. Thus, it is possible that the WSSV envelope protein WSSV067C/VP53A could interact weakly with the cytoskeleton of host cells, but its role in viral infection, replication or spread remains to be tested.

Chitin is an important structural component of the cell walls of fungi and the exoskeletons of many inver- tebrates, such as crustaceans, insects and nematodes. An arthropod chitin-binding domain has been characterized in some chitinases and peritrophic membrane proteins (Shen \& Jacobs-Lorena 1999). However, the chitin-binding Type 2 domain with 6 conserved cysteine residues and several conserved aromatic residues is not found in the cuticular proteins that are also CBPs. Other well characterized CBPs are agglutinins/lectins that exist in almost all living organisms. They are usually proteins or glycoproteins without catalytic activity that have the ability to bind to specific carbohydrates expressed on different cell surfaces (Marques \& Barracco 2000). Agglutinin molecules may occur on the surfaces of viruses, bacteria, yeasts, protozoans and cells of both animals and plants (Sharon \& Lis 1989). Most of the current research emphasizes the possible role of lectins as non-self-recognition molecules in vertebrate and invertebrate immunity (Vasta et al. 1999, Wilson et al. 1999). From studies of lectins conducted on different species of penaeids, the major biological activities were determined to be opsonic activity and agglutination of bacteria (reviewed by Marques \& Barracco 2000). Although the term 'chitinbinding protein' denotes a family of proteins containing one or more chitin-binding domains, it must be emphasized that the binding affinity of these proteins is not restricted to chitin, but may extend to various complex glycoconjugates that contain $\beta$-1,4-linked biopolymers of $\mathrm{N}$-acetylglucosamine (GlcNAc), sialic acid (N-acetyl-D-neuraminic acid; NeuNAc) or Nacetyl-D-galactosamine (GalNAc) as building blocks (Raikhel et al. 1993, Marques \& Barracco 2000). Functions of CBPs can thus range from simple binding (e.g. in the case of lectins) to chitinase activity, or even to antimicrobial and antifungal activities as in the case of tachycitin (Kawabata et al. 1996).

The chitin-binding Type 2 domain is mainly found in animal and baculovirus proteins, whereas Type 1 is found in plants and fungi. Type 2 is characterized by having a 6 -cysteine motif, $C-x(13,20)-C-x(5,6)-C-$ $x(9,19)-C-x(10,14)-C-x(4,14)-C$, and several aromatic residues. Proteins known to contain a chitin-binding Type 2 domain include animal class-II chitinase, tachycitin, peritrophin-A, Drosophila tequila protein and Drosophila hemolectin. All participate in immune responses, except peritrophin- $\mathrm{A}$, which is a component of peritrophic matrices. These are acellular linings in the gut of most insects that comprise proteins and sugar polymers (Suetake et al. 2000, Tjoelker et al. 2000, Gaines et al. 2003).

Alignment of our new CBP to standard databases revealed no similar proteins. The full length PmCBP could not be obtained, even though many methods such as rapid amplification of the cDNA $5^{\prime}$ end (5' RACE) were tried. Nevertheless, the characteristics of 
PmCBP can be inferred, owing to the partial C terminus. Because tissue tropism assays by RT-PCR revealed that PmCBP is a constitutively expressed gene with a chitin-binding Type 2 domain, we speculate that it is not a cuticular protein. It might function like chitinase or lectin. If so, VP53A might play a role in the shrimp immune response. Further research is required to determine whether PmCBP is present on the cell surface or is a secreted protein.

Acknowledgements. This study was supported by the National Council grants NSC 93-2311-B-040-011 and NSC 94-2311-B040-011. We are indebted to Mr. Vince J. Genis and Miss Angela Wang for their helpful criticism of the manuscript.

\section{LITERATURE CITED}

Chen LL, Leu JH, Huang CJ, Chou CM, Chen SM, Wang CH, Lo CF, Kou GH (2002a) Identification of a nucleocapsid protein (VP35) gene of shrimp white spot syndrome virus and characterization of the motif important for targeting vp35 to the nuclei of transfected insect cells. Virology $29344-53$

Chen LL, Wang HC, Huang CJ, Peng SE and 8 others (2002b) Transcriptional analysis of the DNA polymerase gene of shrimp white spot syndrome virus (WSSV). Virology 301: 136-147

Favoreel HW, Van Minnebruggen G, Adriaensen D, Nauwynck HJ (2005) Cytoskeletal rearrangements and cell extensions induced by the US3 kinase of an alphaherpesvirus are associated with enhanced spread. Proc Natl Acad Sci USA 102: 8990-8995

Flegel TW (1997) Special topic review: major viral diseases of the black tiger prawn (Penaeus monodon) in Thailand. World $\mathrm{J}$ Microbiol Biotech 13:422-433

Gaines PJ, Walmsley SJ, Wisnewski N (2003) Cloning and characterization of five cDNAs encoding peritrophin-A domains from the cat flea, Ctenocephalides felis. Insect Biochem. Mol Biol 33:1061-1073

Gouin E, Welch MD, Cossart P (2005) Actin-based motility of intracellular pathogens. Curr Opin Microbiol 8:35-45

Kawabata S, Nagayama R, Hirata M, Shigenaga T and 6 others (1996) Tachycitin, a small granular component in horseshoe crab hemocytes, is an antimicrobial protein with chitin-binding activity. J Biochem 120:1253-1260

Lehmann MJ, Sherer NM, Marks CB, Pypaert M, Mothes W (2005) Actin- and myosin-driven movement of viruses along filopodia precedes their entry into cell. J Cell Biol 170: 317-325

Liu WJ, Yu HT, Peng SE, Chang YS and 9 others (2001) Cloning, characterization and phylogenetic analysis of a shrimp white spot syndrome virus (WSSV) gene that encodes a protein kinase. Virology 289:362-377

Lo CF, Kou GH (1998) Virus associated white spot syndrome of shrimp in Taiwan: a review. Fish Pathol 33:365-371

Lo CF, Leu JH, Ho CH, Chen CH and 8 others (1996a) Detection of baculovirus associated with white spot syndrome (WSBV) in penaeid shrimps using polymerase chain reaction. Dis Aquat Org 25:133-141

Lo CF, Ho CH, Peng SE, Chen $\mathrm{CH}$ and 7 others (1996b) White spot syndrome baculovirus (WSBV) detected in culture and captured shrimp, crabs and other arthropods. Dis Aquat Org $27: 215-225$

Lo CF, Hsu HC, Tsai MF, Ho CH, Peng SE, Kou GH, Lightner DV
(1999) Specific genomic fragment analysis of different geographical clinical samples of shrimp white spot syndrome virus. Dis Aquat Org 35:175-185

Lu L, Kwang J (2004) Identification of a novel shrimp protein phosphatase and its association with latency-related ORF427 of white spot syndrome virus. FEBS Lett 577:141-146

Marques MRF, Barracco MA (2000) Lectins, as nonself-recognition factors, in crustaceans. Aquaculture 191: 23-44

Raikhel NV, Lee HI, Broekaert WF (1993) Structure and function of chitin-binding proteins. Annu. Rev. Plant Physiol Plant Mol Biol 44:591-615

Sasaki H, Nakamura M, Ohna T, Matsuda Y, Yuda Y, Nonomura Y (1995) Myosin-actin interaction plays an important role in human immunodeficiency virus type 1 release from host cells. Proc Natl Acad Sci USA 92:2026-2030

Sharon N, Lis H (1989) Lectins as cell recognition molecules. Science 246:227-234

Shen Z, Jacobs-Lorena M (1999) Evolution of chitin-binding proteins in invertebrates. J Mol Evol 48:341-347

Suetake T, Tsuda S, Kawabata S, Miura K, Iwanaga S, Hikichi K, Nitta K, Kawano K (2000) Chitin-binding proteins in invertebrates and plants comprise a common chitin-binding structural motif. J Biol Chem 275:17929-17932

Tjoelker LW, Gosting L, Frey S, Hunter CL, Trong HL, Steiner B, Brammer H, Gray PW (2000) Structural and functional definition of the human chitinase chitin-binding domain. J Biol Chem 275:514-520

Tonganunt M, Phongdara A, Chotigeat W, Fujise K (2005) Identification and characterization of syntenin binding protein in the black tiger shrimp Penaeus monodon. J Biotechnol 120: 135-145

Tsai MF, Lo CF, van Hulten MCW, Tzeng HF and 6 others (2000) Transcriptional analysis of the ribonucleotide reductase genes of shrimp white spot syndrome virus. Virology 277:92-99

Tsai JM, Wang HC, Leu JH, Hsiao HH, Wang AHJ, Kou GH, Lo CF (2004) Genomic and proteomic analysis of 39 structural proteins of shrimp white spot syndrome virus. J Virol 78: 11360-11370

Tsai JM, Wang HC, Leu JH, Wang AHJ, Zhuang Y, Walker PJ, Kou GH, Lo CF (2006) Identification of the nucleocapsid, tegument, and envelope proteins of the shrimp white spot syndrome virus virion. J Virol 80:3021-3029

Vasta GR, Quesenberry M, Ahmed H, O'Leary N (1999) C-type lectins and galectins mediate innate and adaptive immune functions: their roles in the complement activation pathway. Dev Comp Immunol 23:401-420

Wang $\mathrm{CH}$, Lo CF, Leu JH, Chou CM and 6 others (1995) Purification and genomic analysis of baculovirus associated with white spot syndrome (WSBV) of Panaeus monodon. Dis Aquat Org 23:239-242

Wang Z, Chua HK, Gusti AA, He F, Fenner B, Manopo I, Wang H, Kwang J (2005) RING-H2 protein WSSV249 from white spot syndrome virus sequesters a shrimp ubiquitin-conjugating enzyme, PvUbc, for viral pathogenesis. J Virol 79: $8764-8772$

Wilson R, Chen C, Ratcliffe NA (1999) Innate immunity in insects: the role of multiple, endogenous serum lectins in the recognition of foreign invaders in the cockroach, Blaberus discoidalis. J Immunol 162:1590-1596

Wongteerasupaya C, Vickers JE, Sriurairatana S, Nash GL and 6 others (1995) A non-occluded, systemic baculovirus that occurs in cells of ectodermal and mesodermal origin and causes high mortality in black tiger prawn Penaeus monodon. Dis Aquat Org 21:69-77

Xie X, Yang F (2005) Interaction of white spot syndrome virus VP26 protein with actin. Virology 336:93-99

Submitted: August 16, 2006; Accepted: November 12, 2006

Proofs received from author(s): February 22, 2007 